\title{
Design of a gridded cusp gun for a W-band gyro-TWA
}

\author{
Liang Zhang, Craig R. Donaldson, Adrian W. Cross, Alan D. R. Phelps, and Wenlong He \\ Department of Physics, SUPA, University of Strathclyde \\ Glasgow, Scotland, UK, G4 0NG
}

\begin{abstract}
This paper reports the design and optimization of a gridded cusp electron gun for a W-band gyrotron traveling wave amplifier. By applying positive or negative biasing potentials to additional electrodes that are placed in front of the emitter, the electron beam can be switched on and off quickly and easily. In simulations, an optimal velocity ratio (alpha) of 1.12 with an alpha spread of $\sim \mathbf{1 0 . 7 \%}$ was achieved when the gridded-type gun was operated at a beam voltage of $40 \mathrm{kV}$ and a current of $1.7 \mathrm{~A}$.
\end{abstract}

\section{INTRODUCTION}

$\mathrm{T}$ here are various ways to switch the output of the microwave vacuum electronic devices on and off. One is to apply a pulsed voltage between cathode and anode. However, it is difficult to achieve fast switching when the operating voltage is high. The other way is to introduce an additional voltage-biased electrode between the cathode and anode. For example, in traveling wave tubes, a thin gridded electrode made from molybdenum or graphite is placed immediately in front of the emitter to switch on and off the electron beam. The gridded electron guns are mostly Pierce-type that generate a solid cylindrical beam [1]. Designing a gridded cusp electron gun is new and much more challenging, as the influence of the gridded electrode has to be minimized.

An annular beam is generated by the cusp electron gun. In order to keep a good beam quality and reduce the electron beam velocity spread, a thin emitter is preferred. For a cusp gun designed for a millimeter wave microwave vacuum electronic devices, the emitter thickness was normally about $0.5 \mathrm{~mm}$. The gridded structure used for the Pierce gun is inefficient in this case. Therefore in this paper for the cusp electron gun, a simple structure of using modulation electrodes was employed. A similar concept has been used in magnetic injection guns (MIGs) to provide an extra way to improve the beam quality [2]. To turn on and off the electron beam quickly using a low biasing potential, the modulation electrodes are preferred to be placed close to the emitter.

\section{DESIGN OF THE GRIDDED CUSP GUN}

The design of the gridded cusp electron gun was based on a previously developed cusp electron gun used in two W-band gyro-devices, a gyrotron backward wave oscillator (gyro-BWO) [3] and a gyrotron traveling wave amplifier (gyro-TWA) [4-7]. Both of them uses a helically corrugated waveguide $[8,9]$ as the interaction region. The cusp electron gun for the gyro-devices will be upgraded with a gridded one to allow better control of its output [10-12]. Therefore its geometry was adopted from the existing one, as shown in Fig. 1. To allow the fast beam switching, a small biasing voltage of $1 \mathrm{kV}$ between the cathode and the modulation electrode was used. Two concentric modulation electrodes, with an annular gap in between for the electron beam to pass, were formed surrounding the cathode.
They have the same biasing voltages and can be electrically regarded as one single electrode. The modulation electrodes have a similar outside profile as the cusp gun without gridded, therefore the previous experience can be reused.

The initial parameters of the electron gun geometry and the magnetic field can be evaluated from the theory, they are listed in Table 1.

TABLE I OPERATING PARAMETERS OF THE TRIODE CUSP GUN

\begin{tabular}{lll}
\hline \hline Symbol & \multicolumn{1}{c}{ QUANTITY } & \multicolumn{1}{c}{ Value } \\
\hline$V_{0}$ & Cathode voltage & $-40 \mathrm{kV}$ \\
$V_{m}$ & Modulation voltage & $-39 \mathrm{kV}$ \\
$I_{0}$ & Emitted beam current & $>1.7 \mathrm{~A}$ \\
$V \perp / V_{/ /}$ & Alpha value & 1.1 \\
$B_{c}$ & Magnetic field at the cathode & $-3.6 \mathrm{mT}$ \\
$R$ & Emitter radius & $6.0 \mathrm{~mm}$ \\
$\Delta R$ & Emitter thickness & $0.5 \mathrm{~mm}$ \\
$B_{0}$ & Magnetic field at the flat region & $1.84 \mathrm{~T}$ \\
$R_{0}$ & Average beam radius & $0.28 \mathrm{~mm}$
\end{tabular}

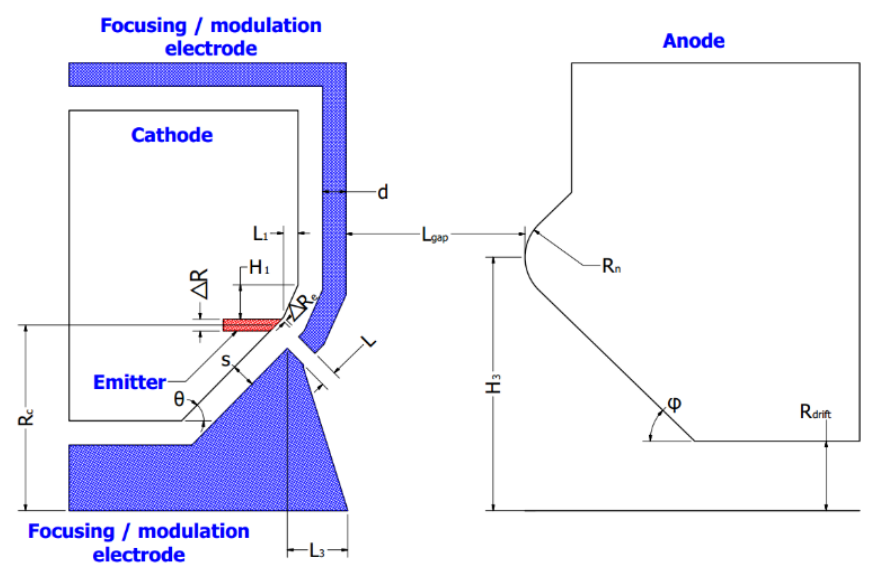

Fig. 1 The geometric model of the triode-type cusp electron gun.

To accurately represent the thin modulation electrodes and curved shapes in the simulation, the finite element simulator Vector Fields OPERA was used to simulate the beam trajectories of the gridded cusp electron gun.

The electric and magnetic fields have to match with each other to obtain a small alpha (transverse-to-axial velocity ratio) spread. Fortunately, it has been concluded that through numerical optimizations earlier that by with a given suitable magnetic field profile, there exists an optimal electron gun geometry. Therefore the same coil setup of the cusp gun without the gridded structure can be used. It reduces the number of free parameters and the previous experience will help to find an optimal structure.

A multiple-objective optimization routing was used in the design. Besides the 8 parameters from the electron gun geometry, therefore are additional two parameters on the 
magnetic field profile, to shift the coil position and adjust the magnetic field strength at the cathode region. The design goal was to achieve minimum alpha spread (counted as the full width at half maximum at the alpha distribution of the electron beam) at the given beam parameters listed in Table 1 .

\section{SimULATION RESULTS}

Fig. 2 and Fig. 3 show the simulation results of the optimized cusp electron gun. The beam alpha values at the last $5 \mathrm{~mm}$ of the simulation region were exported to get the alpha distribution, which is shown in Fig. 3. The full width at half maximum (FWHM) is 0.12 and the central value of alpha is 1.12. The alpha spread is about $10.7 \%$ [13].

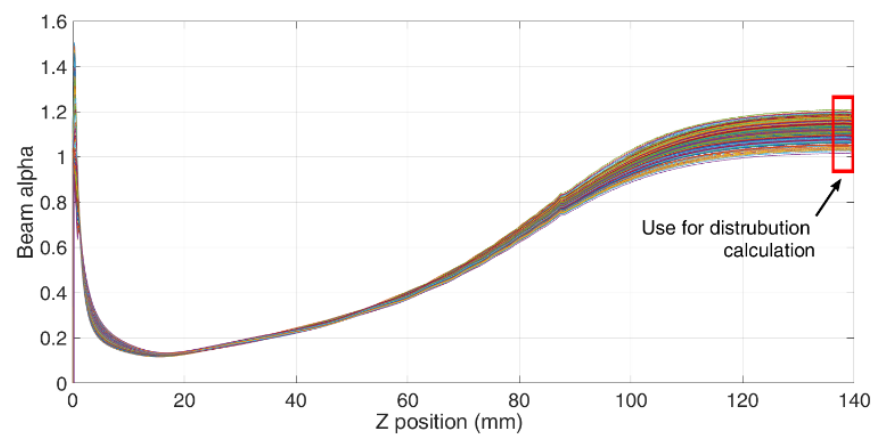

Fig. 2 The simulated beam alpha as a function of the axial position.

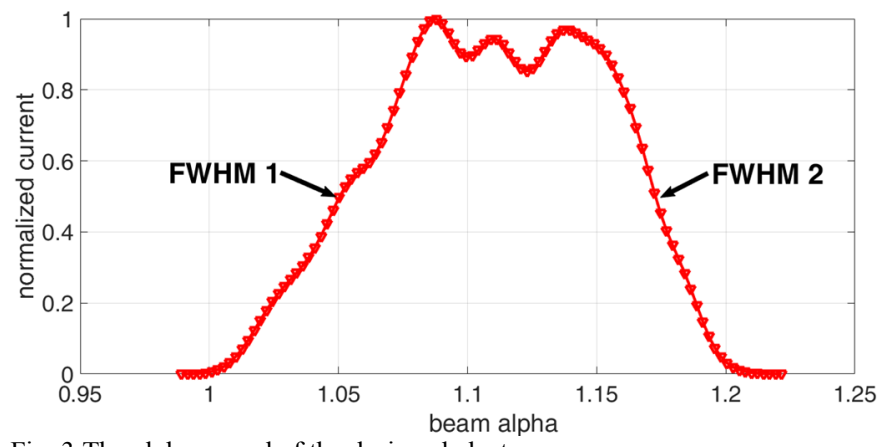

Fig. 3 The alpha spread of the designed electron gun.

The optimized results showed that with a control voltage of $\sim 1 \mathrm{kV}$, an alpha center of 1.12 and a spread about $10 \%$ was achieved. In the simulation, when the electron gun is turned on, the emitted beam current was $\sim 1.7 \mathrm{~A}$. By simulating the electron gun at different control voltages, it was found that the electron beam could be completely switched on at $600 \mathrm{~V}$. The optimal beam quality occurs if the biasing voltage is in the range of $950-1050 \mathrm{~V}$.

\section{ACKNOWLEDGMENTS}

The authors would like to thank Technology Facilities Council (STFC) (research Grant No. ST/P001890/1) for supporting this work.

\section{REFERENCES}

A. S. Gilmour, Klystrons, traveling wave tubes, magnetrons, crossed-field amplifiers, and gyrotrons (Artech House microwave library). Boston, MA: Artech House, 2011, pp. xviii, 859 p. S. Albertia, A. Arnold, E. Borie, G. Dammertz, V. Erckmann, P. Garin, E. Giguet, S. Illy, G. Le Cloarec, Y. Le Goff, R. Magne, G. Michel, B. Piosczyk, C. Tran, M. Q. Tran, M. Thumm, and D.
Wagner, "European high-power $\mathrm{CW}$ gyrotron development for ECRH systems," Fusion Engineering and Design, vol. 53, no. 1-4, pp. 387-397, 1// 2001. DOI: S0920-3796(00)00514-7

[3] W. He, C. R. Donaldson, L. Zhang, K. Ronald, P. McElhinney, and A. W. Cross, "High Power Wideband Gyrotron Backward Wave Oscillator Operating towards the Terahertz Region," Phys. Rev. Lett., vol. 110, no. 16, p. 165101, 2013. DOI: 10.1103/PhysRevLett.110.165101

W. He, C. R. Donaldson, L. Zhang, K. Ronald, A. D. R. Phelps, and A. W. Cross, "Broadband Amplification of Low-Terahertz Signals Using Axis-Encircling Electrons in a Helically Corrugated Interaction Region," Phys. Rev. Lett., vol. 119, no. 18, p. 184801, Oct. 2017. DOI: 10.1103/PhysRevLett.119.184801

[5] L. Zhang, C. R. Donaldson, P. Cain, A. W. Cross, and W. He, "Amplification of frequency-swept signals in a W-band gyrotron travelling wave amplifier," IEEE Electron Device Letters, pp. 1-1, 2018. DOI: 10.1109/LED.2018.2836868

L. Zhang, W. He, C. R. Donaldson, G. M. Smith, D. A. Robertson, R. I. Hunter, and A. W. Cross, "Optimization and Measurement of a Smoothly Profiled Horn for a W-Band Gyro-TWA," IEEE Trans. Electron Devices, vol. 64, no. 6, pp. 2665-2669, June 2017. DOI: 10.1109/TED.2017.2687949

C. R. Donaldson, P. McElhinney, L. Zhang, and W. He, "Wide-Band HE11 Mode Terahertz Wave Windows for Gyro-Amplifiers," IEEE Transactions on Terahertz Science and Technology, vol. 6, no. 1, pp. 108-112, June 2016. DOI: 10.1109/TTHZ.2015.2495221

L. Zhang, S. V. Mishakin, W. He, S. V. Samsonov, M. McStravick, G. G. Denisov, A. W. Cross, V. L. Bratman, C. G. Whyte, C. W. Robertson, A. R. Young, K. Ronald, and A. D. R. Phelps, "Experimental Study of Microwave Pulse Compression Using a Five-Fold Helically Corrugated Waveguide," IEEE Trans. Microwave Theory Techn., vol. 63, no. 3, pp. 1090-1096, 2015. DOI: 10.1109/TMTT.2015.2393882

[9] L. Zhang, W. He, K. Ronald, A. D. R. Phelps, C. G. Whyte, C. W. Robertson, A. R. Young, C. R. Donaldson, and A. W. Cross, "Multi-Mode Coupling Wave Theory for Helically Corrugated Waveguide," IEEE Trans. Microwave Theory Techn., vol. 60, no. 1, pp. 1-7, Jan. 2012. DOI: 10.1109/TMTT.2011.2170848

[10] C. R. Donaldson, W. He, A. W. Cross, F. Li, A. D. R. Phelps, L. Zhang, K. Ronald, C. W. Robertson, C. G. Whyte, and A. R. Young, "A cusp electron gun for millimeter wave gyrodevices," Appl. Phys. Lett., vol. 96, no. 14, p. 141501, 2010. DOI: 10.1063/1.3374888

[11] C. R. Donaldson, W. He, A. W. Cross, A. D. R. Phelps, F. Li, K. Ronald, C. W. Robertson, C. G. Whyte, A. R. Young, and L. Zhang, "Design and Numerical Optimization of a Cusp-Gun-Based Electron Beam for Millimeter-Wave Gyro-Devices," IEEE Trans. Plasma Sci., vol. 37, no. 11, pp. 2153-2157, 2009. DOI: 10.1109/TPS.2009.2031470

[12] L. Zhang, W. He, C. R. Donaldson, and A. W. Cross, "Investigation on the optimal magnetic field of a cusp electron gun for a W-band gyro-TWA," Physics of Plasmas, vol. 25, no. 5, p. 053104, 2018/05/01 2018. DOI: $10.1063 / 1.5027070$

[13] L. Zhang, C. R. Donaldson, and W. He, "Optimization of a triode-type cusp electron gun for a W-band gyro-TWA," Physics of Plasmas, vol. 25 , no. 4, p. $043120,2018 / 04 / 01$ 2018. DOI: $10.1063 / 1.5028262$ 